\title{
REPRESENTAÇÕES SOCIAIS DE ESTUDANTES DO ENSINO FUNDAMENTAL DA REDE PÚBLICA DE ENSINO ACERCA DA VIOLÊNCIA NA ESCOLA*
}

\author{
Ana Flavia Souza Santana, \\ da Universidade Estadual de Feira de Santana
}

\begin{abstract}
RESUMo: Esta pesquisa tem como objetivo descrever a representação social que estudantes do ensino fundamental de duas escolas públicas da rede estadual de ensino de Salvador/BA fazem da violência na escola, identificando os significados associados a esta violência, suas raízes e possível prevenção. Os dados foram levantados através de entrevista semiestruturada, que versou sobre a violência em geral, suas interfaces com a escola, as possíveis causas e prevenção etc. Os dados levantados possibilitaram compreender que a violência está vinculada à agressão física, à criminalidade, sendo o próprio aluno o responsável primeiro pela produção da violência. As representações sobre a violência na escola trazem significados como desrespeito e discriminação, assim como violência escolar, agressão física, verbal e psicológica. PalaVRas-chave:Violência. Violência na escola. Representações sociais. Estudantes.
\end{abstract}

\section{INTRODUÇÃO}

O agravamento das condições de pobreza, o alargamento da exclusão, a diminuição progressiva da garantia dos direitos humanos, somados aos vestígios de outros elementos da globalização, como a fragmentação social, a massificação e a individualização, têm trazido consequências graves à sociedade, como o surgimento de uma forma alternativa às normas sociais de determinados grupos, invertendo a lógica do processo civilizatório: a violência. Havendo, inclusive, um consenso de que "a exclusão e a miséria

\footnotetext{
* Artigo recebido em 8/9/2011 e aprovado em 30/11/2011.
} 
de grande parte da população global conduz à violência como resposta a tal processo e elemento recorrente em tal contexto" (DAVID, 1997, p. 24).

Nesta mesma vertente, que considera a violência como resposta a uma situação crítica de desigualdade social, Adorno e Pinheiro (1993, p. 11) afirmam que os segmentos populacionais desprivilegiados submetemse "a restrições e constrangimentos de toda sorte, que comprometem o direito à vida e limitam seu acesso aos bens e ao patrimônio da civilização, desumanizando-o, embrutecendo-o e instituindo a violência como a única linguagem possível, aquela que exclui o diálogo e o apelo à razão".

A violência, portanto, é um fenômeno social crescente e tem inquietado a todos por sua expansão em lugares antes pouco afetados e pela constante emergência de novas modalidades de agressão, sejam elas físicas ou morais. O questionamento acerca do que tem fomentado tal expansão abre cortinas para um grande rol de possibilidades e, ao contrário de uma imagem esclarecedora, a violência se apresenta como um fenômeno complexo e controverso. Para tentar compreendê-lo, é preciso não apenas descrever quais seriam suas causas e consequências, mas buscar entender os vários mecanismos históricos, sociais, políticos e culturais que se inter-relacionam, compondo aquilo que se está chamando de violência.

Apesar das questões sociais vinculadas à pobreza, exclusão, não garantia de direitos e desigualdades sociais serem premissas básicas para a compreensão da violência, não se pode restringi-la a um fenômeno manifestado unicamente nas classes sociais pobres. De acordo com Camacho (2001, p. 125),

a violência [...] está presente em toda sociedade e não se restringe a determinados espaços, a determinadas classes sociais, a determinadas faixas etárias ou a determinadas épocas. É equivocado pensar que ela se vincula apenase diretamente à pobreza, aos grandes centros urbanos, aos adultos e aos dias de hoje. Verifica-se, por exemplo, o crescimento das práticas da violência entre os jovens de classes médias e de segmentos privilegiados da sociedade, nos seus diferentes espaços de atuação: na família, na escola ou na rua.

O que se verifica, portanto, é que o momento atual passa, como define David (1997), por uma "desordem social", que fomenta não apenas as expressões de pobreza e desigualdades, mas, principalmente, a mutabilidade das relações sociais de uma maneira geral, desintegrando culturas e famílias, dando lugar ao individualismo e à fragmentação do coletivo. Itani (1998) corrobora essa ideia ao considerar que "a cultura de massa vem destruindo as culturas tradicionais, alterando modos de compreensão do mundo, fragilizando ao mesmo tempo o valor predominante das instituições na 
preservação da condição humana social" (p. 46). Assim, pode-se afirmar que violência não é sinônimo unicamente de pobreza, dos problemas sociais concretos, mas também daquilo que caminha pelo invisível.

Diante do fato de que a violência tem aumentado e ocupado os mais diversos espaços, não se pode deixar de considerar a emergência da violência no âmbito escolar. Este fato, segundo Santos (2001), vem colocar em risco a função social da escola, uma vez que se tem evidenciado que ela se tornou espaço de exploração dos conflitos sociais. Além disso, "a compreensão das relações entre a escola e as práticas da violência passa pela reconstrução da complexidade das relações sociais que estão presentes no espaço social da escola"(SANTOS, 2001, p. 107), sendo necessário um debruçar mais atento aos diversos aspectos que permeiam e fomentam a violência no contexto escolar.

Neste sentido, esta pesquisa teve como objetivo descrever a representação social que estudantes do ensino fundamental ( $6^{\circ}$ ao $9^{\circ}$ ano) de duas escolas públicas da rede estadual de ensino de Salvador/BA fazem da violência na escola, identificando os significados associados a esta violência, bem como suas raízes e possível prevenção.

A teoria das representações sociais forneceu a base necessária para a compreensão de como os estudandes estão concebendo e enfrentando a violência nas escolas, uma vez que as representações sociais são construídas nas relações sociais, nas quais as pessoas interagem reciprocamente, através de práticas de produção de sentidos, estruturando um conjunto de representações compartilháveis e comunicáveis acerca da compreensão de um determinado objeto. Essas representações orientam as ações individuais, tanto em termos das estratégias de ação a serem utilizadas, como das possíveis consequências destas ações. O estudo fundamentado nesta teoria, portanto, favoreceu o delineamento de como um grupo de estudantes de escola pública pensam a violência e, especificamente, a violência nas escolas.

\section{VIOLÊNCIA E A ESCOLA}

Pensar a violência no âmbito escolar é motivo de indignação, visto que esta instituição sempre foi concebida como formadora, como espaço de educação e construção de saberes. Questões relacionadas aos motivos de ter a violência alcançado este espaço fomentam as inquietações de profissionais de diversas áreas como a educação, a psicologia, a sociologia, que buscam compreender o que permeia a ocorrência e a expansão da violência nas escolas.

As pesquisas e discussões desenvolvidas acerca do surgimento da violência na escola têm lançado o debate referente à existência ou não de 
uma violência escolar. Ou seja, há uma violência gerada a partir de uma dinâmica própria da instituição escolar, "que nasce no interior da escola ou como modalidade de relação direta com o estabelecimento de ensino" (SPOSITO, 1998, p. 64)? Ou a escola tem sido mais um lócus de expressão da violência produzida fora dela?

Em relação a este debate, Ristum $(2001$, p. 5) afirma que,

no primeiro caso, trata-se de violência produzida na e pela escola, em função de formas de atuação que estariam propiciando seu aparecimento e manutenção. Já o segundo caso, refere-se a uma reprodução, dentro dos muros escolares, da violência que ocorre na sociedade.

Estas discussões permeiam o problema da legitimação de um objeto de estudo, o qual precisa de delimitações e especificidades. E levando em conta essas dificuldades e discutindo-as, Ristum (2001) propõe que a violência escolar seja entendida como aquela que

envolve membros dos corpos docente e/ou discente e/ou técnico e/ou administrativo e/ou direção e/ou pessoal de apoio, referente a questões escolares administrativas, disciplinares e acadêmicas. Nesta categoria foi também incluída a depredação da escola, praticada tanto por elementos externos à escola como pelos próprios alunos da escola. (p. 134)

Mas a partir de quais indicadores a violência ligada à escola ganhou visibilidade? Segundo Sposito (2001, p. 90), "é no quadro de uma ampla demanda de segurança por parte dos moradores das periferias dos centros urbanos que o fenômeno da violência nos estabelecimentos escolares tornase visível e passa a acompanhar a rotina do sistema de ensino público". Num contexto em que surge uma preocupação em tratar das condições dos prédios escolares, bem como das depredações, invasões, a violência nas escolas é vista como uma questão de segurança, reivindicando-se, portanto, a proteção dos prédios escolares.

Insuficiente para o arrefecimento da violência, a segurança dos prédios escolares e a melhoria de suas condições deixaram de ocupar o centro das discussões, sendo substituídas pela necessidade de atenção à escola enquanto instituição que estrutura formas de sociabilidade peculiares e particulares.

Pensar a instituição escola implica incluí-la no plano de todas as instituições. Estas se constituem a partir das relações e práticas sociais, as quais são legitimadas enquanto se repetem de tal forma que não há fazer humano fora das instituições, bem como não existem instituições fora das ações e relações sociais (GUIRADO, 1997, citado em AQUINO, 1998). 
Assim, utilizando as palavras de Aquino (1998, p. 19), é necessário ter ciência de que, entendendo a escola como instituição,

não é possível sustentar categoricamente que a escola tão-somente "reproduz" vetores de força exógenos a ela. É certo, pois, que algo de novo se produz nos interstícios do cotidiano escolar, por meio da (re)apropriação de tais vetores de força por parte de seus atores constitutivos e seus procedimentos instituídos/instituintes.

A compreensão da violência que se expande no contexto escolar passa pela complexidade das relações sociais mantidas entre atores e instituição, reciprocamente. Segundo Itani (1998, p. 37), "a literatura recente vem apresentando novas categorias de análise, tentando desvelar como a violência está embutida no sistema educacional, seja no projeto de formação, seja no processo educativo, o qual age como uma violência simbólica na ação pedagógica".

Nessa perspectiva, alguns autores, como Santos (2001), afirmam existir na escola"poderes legitimados", os quais conferem formas de controle social. Estes poderes aparecem mais claramente nas relações entre professor e aluno, através da autoridade conferida ao docente. Tomando emprestado a expressão "poderes legitimados" trazida por Santos, não é demais afirmar que esses poderes se estendem a outras formas, expressas nas relações que se estabelecem entre aluno/professor, aluno/aluno, demais funcionários/ alunos, alunos/demais funcionários etc.; na reprodução acrítica da ideologia dominante; na baixa qualificação dos professores, tanto no aspecto pedagógico, como no financeiro; no sucateamento das escolas, com falta de equipamentos, de condições de trabalho, salas lotadas; na negação da alteridade etc.

Não se pode deixar de esclarecer, entretanto, que ainda que a escola também seja promotora de diversos tipos e modalidades de violência e ainda que reflita a ideologia do sistema sócio-político-econômico, na qual se insere (RISTUM, 2001), a escola não serve unicamente a reproduzir-se sempre a mesma. Sendo uma instituição social, ela se legitima nas relações sociais. Mesmo sendo um espaço de explosão de conflitos, a escola, antes de tudo, configura-se por meio de relações sociais, as quais são intrinsecamente dinâmicas. Desta forma, ela tem o poder de transformar sua própria realidade, desde que se dê conta das brechas das contradições sociais (RISTUM, 2001) que nela se desenrolam. 


\section{REPRESENTAÇÕES SOCIAIS}

Compreendendo a violência como um fenômeno complexo, que abrange questões históricas, sociais e políticas, propõe-se aqui a estudá-lo a partir da teoria das representações sociais, definidas por Jodelet (1989, citada em SÁ, 1993, p. 32), como "uma forma de conhecimento, socialmente elaborada e partilhada, tendo uma visão prática e concorrendo para a construção de uma realidade comum a um conjunto social".

A teoria das representações sociais, portanto, se traduz como via de acesso à compreensão do fenômeno estudado, possibilitando a análise de como a violência na escola é concebida pelos estudantes, uma vez que "o conhecimento estudado via representações sociais é sempre um conhecimento prático, é sempre uma forma comprometida e/ou negociada de interpretar a realidade" (SPINK, 1993, p. 303). Como as representações sociais são construídas em relações, através de práticas de produção de sentidos, "as representações são sempre construções contextualizadas, resultados das condições em que surgem e circulam" (SPINK, 1993, p. 303).

Trata-se de uma teoria que procura superar a dicotomia entre conhecimento científico e senso comum, uma vez que vai além das fronteiras da ciência, levando em conta também o saber do homem comum. "Trata-se, portanto, de uma ampliação do olhar de modo a ver o senso comum como conhecimento legítimo e motor das transformações sociais" (SPINK, 2003, p. 119). Senso comum é entendido por esta autora como "teia de significados capaz de criar efetivamente a realidade social" (1993, p. 303).

As representações sociais engendram práticas, orientam as ações individuais, tanto em termos das estratégias de ação a serem utilizadas, como acerca das possíveis consequências destas ações. Enquanto formas de conhecimento prático, orientadas para a comunicação, a compreensão e o domínio do ambiente social, material e ideal (SÁ, 1993), articulam-se tanto na vida coletiva da sociedade, como nos processos de constituição simbólica, nos quais os sujeitos lutam para dar sentido ao mundo, entendê-lo e nele encontrar seu lugar (JOVCHELOVITCH, 2003).

Pode-se dizer, portanto, que a teoria das representações sociais se constitui como uma via adequada à captação da forma como um grupo de estudantes de escola pública pensa sobre a violência na escola, uma vez que as representações são elaboradas a partir das relações mantidas entre homem e sociedade, mediando as formas como as pessoas agem e enfrentam seu cotidiano. 


\section{Metodologia}

A pesquisa foi desenvolvida a partir da abordagem qualitativa, utilizando como fundamentação a teoria das representações sociais, que se afirma no campo da subjetividade e do simbolismo (MINAYO e SANCHES, 1993). De acordo com Serapioni (2000, p. 190), os métodos qualitativos têm a capacidade de fazer emergir aspectos novos, de ir ao fundo do significado e de situar-se na perspectiva do sujeito, descobrindo novos nexos e explicando significados.

A coleta de dados foi realizada em duas escolas públicas da rede estadual de ensino, localizadas em dois bairros diferentes, sendo um periférico, na região do subúrbio, e outro situado mais próximo às áreas mais valorizadas da cidade de Salvador/BA. Ambas atendem o entorno do bairro. $O$ entorno de cada uma das escolas é composto por áreas consideradas violentas pela população em geral, independente de estarem localizadas na periferia ou em região valorizada.

As escolas selecionadas trabalham apenas com o ensino fundamental; para esta pesquisa, foram considerados alunos do $6^{\circ}$ ao $9^{\circ}$ ano.

A inserção na escola se deu através de contato com a direção, quando foram explicitados os objetivos da pesquisa e solicitada a permissão para a realização da coleta de dados. Com a permissão, a direção assinava o Termo de Consentimento Informado, a fim de serem resguardadas questões éticas.

Os estudantes foram selecionados aleatoriamente, entre os que estavam disponíveis no momento da pesquisa, ou seja, que não estavam em aula (horário do intervalo, antes do início ou no término de uma aula). Participaram da pesquisa 16 estudantes -10 meninas e 6 meninos,- 8 de cada escola, sendo 2 alunos de cada série. A faixa etária dos entrevistados variou entre 10 a 22 anos. Todos eram moradores do entorno do bairro onde a escola se localiza.

Para a coleta de dados, foram realizadas entrevistas individuais, semiestruturadas, seguindo um roteiro que abordava questões ligadas ao entendimento sobre violência, sua conceituação, prevenção, formas de enfrentamento etc. Realizadas nas dependências da escola, em momentos de disponibilidade do estudante, como descrito anteriormente, foram gravadas em áudio e posteriormente transcritas para a análise das informações.

Para o procedimento de análise dos dados, trabalhou-se com o modelo teórico-metodológico de análise das práticas discursivas descrito por Spink (1999), que toma as práticas discursivas como produção de sentidos, num constante processo de trocas simbólicas, dado e construído pelas relações 
sociais do cotidiano. Assim, esta abordagem torna-se um caminho privilegiado para entender como as pessoas constroem as representações sociais acerca de determinado objeto, bem como quais são essas representações e qual é essa dinâmica da produção de sentidos.

\section{ANÁLISE DOS DADOS}

Com base nas informações colhidas no decorrer da pesquisa, sobre como os estudantes pensam e representam a violência na escola, foram identificados alguns elementos que ajudam a delinear o perfil representacional destes indivíduos, alunos de escolas públicas de Salvador/BA e moradores de bairros considerados violentos pela população em geral, no que se refere à violência na escola, e assim como aos demais elementos a ela associados.

Como as entrevistas trouxeram conteúdos bastante complexos, para uma melhor compreensão das representações sociais, a análise foi sendo desenvolvida a partir da divisão dos discursos em unidades ou categorias significativas. Tais unidades ou categorias foram identificadas de acordo com os objetivos da pesquisa, elementos fundamentais para a elaboração do perfil das representações sobre a violência na escola, apontando para questões sobre o que permeia a constituição desta violência, quais suas possíveis raízes e também o que pode favorecer sua prevenção.

\subsection{A violência}

O conceito de violência, sempre muito difícil, está sempre em discussão entre os pesquisadores do tema. Discorrendo a esse respeito, Debarbieux (2001, p. 163) afirma: "o objeto científico parece permanecer à espera de uma definição precisa. $O$ debate permanece considerável entre os partidários de uma definição restrita e os pesquisadores que preferem uma abordagem mais extensiva".

As discussões conceituais permanecem em função da complexidade do fenômeno, sendo difícil encontrar uma extensão de palavras que dê conta de maneira completa e acertada do que viria a ser violência.

Dessa forma, a indefinição é companheira das compreensões acerca do fenômeno da violência. Apesar da necessidade didática, uma definição fechada e consensual pode ser desnecessária, uma vez que, como diz Debarbieux (2001), nenhum vocabulário "descobre" a verdade do objeto a que ele se refere. As definições se assentam sobre o caráter variável do contexto, da história ou da situação social e não sobre uma apresentação de atributos e essências individuais. 
Continuando com Debarbieux e parafraseando sua explanação acerca da delinquência juvenil tratada por Chamboredon, é importante dizer que o erro de algumas abordagens que lidam com a violência é considerá-la como uma entidade homogênea e invariável. Esse tipo de consideração neutraliza a importância dos diversos mecanismos que constituem o fenômeno, o que impede a compreensão da gênese da violência.

A premissa básica desta pesquisa é a crença de que a forma como as pessoas representam e dão significados às coisas e fenômenos é determinante da maneira com que elas lidam com o objeto desses significados. As representações sociais engendram práticas, daí ser tão necessário conhecêlas. No caso específico da violência, por exemplo, as políticas de prevenção e repressão devem considerar as especificidades das compreensões de determinado grupo, de determinada demanda.

Assim, será apresentada aqui a maneira particular com que estudantes de escolas públicas de Salvador compreendem a violência e a definem, levando em conta o que esses atores sociais consideram como violência.

As definições foram divididas em dois tipos:

1) Ênfase nas formas como a violência está sendo manifestada e nos instrumentos através dos quais ela pode ser expressa:

Rapaz, violência pra mim... eu acho assim, que é motivo de guerra! Que não briga só com o outro, ...aí vão lá, volta com cinco, seis, tudo com arma na cintura... semana passada mataro um de 15 anos aí...

...briga, tiro, assalto, coisa assim...

2) Definição mais ampla e abstrata:

Violência é um ato de agressão física e moral, assim, que as pessoas têm uns com os outros.

Falta de compaixão, briga, desamor, desafeto.

Pra mim é ato de pessoas estarem brigando, no caso, de agredir verbalmente ou até fisicamente e estarem acabando com si mesmo, com o próximo, estar destruindo com o patrimônio, com seu jeito de ser, sua realidade, pra tá mostrando seu lado mais agressivo.

Como se observa, as compreensões da violência, para este grupo de estudantes, giram em torno da agressão física, desdobrando-se em formas de violência vinculadas à criminalidade, como mostram os exemplos. Como residem em bairros considerados violentos, nas entrevistas eles retratavam aquilo que vivem em seu cotidiano. 


\subsection{Violência na escola}

Apesar de também haver inúmeras discussões relativas a uma definição de violência na escola, foi apresentada neste relato de pesquisa uma definição de Ristum (2001), que delineia de maneira clara e didática os limites que circunscrevem a chamada violência escolar. Levando em consideração as características apresentadas na referida definição, apresenta-se o que os estudantes expressaram como sendo violência na escola:

os menino ficam brigando, respondendo a tia, rumano cadeira pra cima. Quando a professora pede silêncio... xinga a professora, levam... como agora mesmo, levam... tão levando bomba pra estourar aqui no banheiro do colégio, é... levam objetos cortantes... aí brinca de rumar uma cadeira no outro...

A falta de respeito aos professores, também aos alunos, discriminação, é... guerra...

...é preconceito, brigas, é esse negócio de esculhambação, ficar tirando onda das pessoas, dizendo que não tem condições de comprar uma coisa boa...

Nas representações sociais acima, aparece a violência contra o professor e entre alunos. Além das agressões físicas apresentadas nos conceitos da violência em geral, as representações sociais acerca da violência na escola abrangem outras dimensões da violência, como a verbal e psicológica, manifestadas através da discriminação, da falta de respeito e da negação da alteridade entre os alunos.

\subsection{Causas da violência}

Diversos foram os motivos apresentados pelos estudantes como causadores da violência. Assim, para facilitar a compreensão, foram agrupados em oito categorias:

1) Situações escolares que facilitam o aparecimento da violência entre alunos:

na quadra mesmo, fica brincando com o pessoal de jogar pedra no outro e um num gosta aí acontece logo uma coisinha.

aqui mesmo, na hora do "baba" mesmo, tem menino que é esquentadinho, não pode tomar porrada, aí logo uns xinga outro no corredor.

2) Problemas familiares:

Às vezes eu acho que é problemas familiares, porque assim, muitas pessoas, muitos alunos aqui tem problemas nas famílias, assim, pais alcoólatras, mães assim que não tem muitas condições financeiras e aí eles fazem isso aí. 
3) Discriminação:

Aparece mais assim por causa de discriminação.

4) Más amizades:

É até amizade...

Os amigos, né, que dão maus conselhos pra eles, eles vê também as pessoas fazendo e acha que é engraçado, que tem que fazer.

5) Falta de atenção dos pais:

Falta de atenção... na parte dos pais, falta de respeito, de carinho...

...eu acho que também é falta de diálogo com os pais. Acho que os pais não conversam com os filhos, entendeu. Também acho assim, no dia da reunião de pais, os alunos deveriam vir também pra escola, entendeu. Sei lá, pra participar, saber, porque na maioria das vez os pais chegam em casa conversam, mas pra eles tanto faz.

6) Atitudes do pessoal da escola:

...e o diretor na sala dele resolvendo algumas coisas e a vice não podia sair pra falar.

Eu acho que os professores tão dando muita liberdade pra os alunos, eles estão dando motivo pros alunos serem assim, por tratar mal os alunos.

7) Roubo:

Roubo... os cara aqui da 6a mesmo, os maiores roubam alguma coisa da 7a,

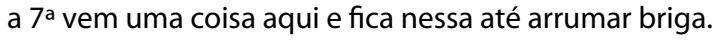

8) Características da adolescência:

...adolescentes que são falhos e que a gente tem muita coisa aqui na cabeça que fica tudo muito confuso.

...esses meninos novo que é muito arrogante, quer ser homem, quer se amostrar, quer fazer coisa que não tem nada a ver, então isso faz com que venha acontecer uma violência.

Apesar de a literatura fazer uma discussão acerca das questões macrossociais como causas da violência e de afirmar a indissociabilidade dessas questões para a compreensão da violência, os estudantes entrevistados não expressam essa percepção. Apesar de viverem em condições de precariedade, não se referem em nenhum momento das entrevistas à pobreza, à falta de recursos como produtoras de violência. 
As causas da violência na escola, segundo a concepção desses estudantes, passam pelas questões mais próximas a esses indivíduos, como as situações e circunstâncias que julgam ser facilitadoras do aparecimento da violência, dependendo, assim, deles mesmos ou das pessoas próximas a eles, como amigos, familiares e pessoal da escola.

Observa-se, entretanto, que mesmo os estudantes se referindo apenas a aspectos de mais proximidade a eles, várias são as possibilidades de causas da violência na escola apontadas.

\subsection{Prevenção}

Esta unidade refere-se à percepção dos estudantes sobre a prevenção da violência escolar. Apesar da questão ter enfatizado o papel da escola neste processo, muitos estudantes apresentaram considerações sobre a importância da participação da família no contexto escolar para a prevenção da violência.

Entretanto, houve também quem não acreditasse na possibilidade de prevenção da violência escolar.

1) Descrença:

Rapaz, praticamente não. Não é só aqui, é fora também.

Acaba não... acho que mesmo... por acaso, tem uma briga lá... aí... tem uma briga aí no corredor... a diretora vem conversa, chama os pais, não sei quê, mas do lado de fora acontece. Eles chamam, outros amigo, que fica tudo do lado de fora pra pegar o aluno pra bater... não tem como aqui prevenir.

Aqui? Tá difícil. Eu acho... que... sei lá, eu acho que não. Porque os menino já se acostumaram e acho que não vai tirar esse vício não... duvido, eu duvido.

Como foi percebido, alguns estudantes falaram da dificuldade de lidar com a violência na escola e preveni-la, porque muitas vezes ela é externa à escola. Esse é um fator importante. Como foi dito, há uma discussão referente ao reconhecimento da violência escolar como objeto específico, mas principalmente predomina a compreensão de que a violência alcança as várias instâncias e situações que a promovem. E a violência externa à escola é uma dessas várias instâncias que fomentam o surgimento da violência também no âmbito escolar.

2) Papel da escola:

Este tópico foi divido de acordo com o que os estudantes abordaram como formas de prevenção. 


\section{1) Reunião de pais:}

Sei lá, uma reunião, assim, toda semana, de pais dos alunos falando o que os aluno tão fazendo. Assim melhora, que aqui chama uma vez ou outra os pais pra vim aqui.

Pode, eu acho que ela pode fazer muita coisa, né... assim, fazer... tipo assim, uma estatística com os alunos e assim, falar... pedir pros pais virem aqui pra conversar.

\section{2) Punição e ameaça de punição:}

Pode sim, uma punição... Suspensão, essas coisa.

É... botar todo mundo na sala, dar a chave ao professor e trancar logo a porta pra ninguém sair.

\section{3) Eventos esportivos e culturais:}

eu estudei em vários colégios... todo ano tinha campeonato lá nas salas, outras pessoas de outros colégios, agitavam vários colégios, fazia campeonato, tinha palestra, pai toda semana, salas de computadores, coisa que aqui não tem.

eventos, eu digo assim, de uma maneira... teatro, por acaso, teatro falando sobre jovens, devia ter várias palestras, chama as salas... no mês, ter uma vez, duas vez no mês, ter uma palestra sobre violência, botar um vídeo... Acho que dessa maneira acho que conseguia diminuir mais um pouco a violência.

\section{4) Atitude do pessoal da escola:}

Eu acharia que o que falta na escola é compreeensão dos professores com a gente... a gente fala aqui agora, tá falando, por exemplo, assim, a gente pede uma folha de papel de ofício, não tem, pede... uma tesoura... peça a fulano, a sicrano... não dá atenção.

ajudando os alunos a serem mais civilizados, a serem mais educados, não apreendendo, não gritando com os alunos já é uma boa ajuda.

\section{5) Segurança:}

Acho que se a gente botar aquele negócio que tem em banco... é, detector de metal, isso e mais seguranças.

aqui devia ter uma segurança melhor, né, ter policiamento, policial aqui andando, porque tem aluno as vez que vem com droga aqui pro colégio, outros vêm armado.

não deixar aluno de outra escola entrar no colégio... olhar... botar algum funcionário lá... por exemplo, a manhã toda olhando lá pra num deixar ninguém subir... 


\section{6) Condições locais e de ensino:}

mas tem que melhorar... a gente tá numa sala mesmo que é apertadíssima, sala que é pra ter 25 alunos tem mais...

De ter tem, uma sala ali que malmente a gente tem aula de informática duas vez na semana, mas professor nunca foi lá... tem computador ali, mas não adianta em nada.

3) Papel dos pais:

eu queria assim, que os pais tivessem mais colaboração com seus filhos e, assim, participassem das reunião, porque vêm muito poucas pessoas pras reuniões que tem.

muitos pais não orientam os filhos com muitas coisas e os professores podiam também estar ajudando, sempre alerta assim, com a educação dos adolescentes que são falhos e que a gente tem muita coisa aqui na cabeça que fica tudo muito confuso.

\subsection{Alunos}

No discurso apresentado pelos estudantes ficou bastante claro que consideram os próprios alunos como responsáveis pela violência que emerge na escola.

Na mesma hora que tá na sala de aula, professor educando, ensinando a gente que não é pra fazer isso, no outro dia a gente tá fazendo a mesma coisa.

os menino ficam brigando, respondendo a tia, rumano cadeira pra cima [...], xinga a professora, levam... como agora mesmo, levam, tão levando bomba pra estourar aqui no banheiro do colégio, é... levam objetos cortantes...

como o povo diz, né, a escola é dos alunos, então eles fazem de tudo pra que nós assim... a gente não faça isso, só que mesmo assim os alunos não respeitam, eles acham que os professores, os diretores, assim, tão tudo mandando, fala demais, não faz questão assim...

nunca dá certo assim com os alunos, eles não procuram obedecer, eles sempre tem que dizer, 'ah, problema, tô nem aí, eu não vou ganhar ponto por causa disso', essas coisa assim.

Até os professores têm medo de ficar na própria sala de aula com os alunos.

Eu vi muito aluno vim praqui armado...

É interessante observar que, apesar de indicarem como formas de prevenção da violência na escola aspectos como a punição ou a ameaça de 
punição, parece haver uma contradição entre as formas de prevenção e o comportamento dos alunos, uma vez que ao mesmo tempo que apresentam a punição como medida de prevenção, afirmam: "dá suspensão, chama os pais, mas não adianta. Eles continuam fazendo a mesma coisa". Parece não ficar claro para eles que "fazer a mesma coisa" pode ser um indicador de que alguns dos tipos de prevenção apontados por eles não estão dando resultado.

O fato de esse considerarem os próprios alunos como promotores da violência na escola justifica a necessidade de pesquisas junto aos alunos, pois além de estarem diretamente ligados ao cenário da escola e serem, consequentemente, corresponsáveis por essa violência, eles próprios se consideram promotores da violência no ambiente escolar.

É necessário, então, organizar a participação de estudantes na reflexão e elaboração de medidas e políticas de prevenção da violência nas escolas, inserindo-os nesse processo como responsáveis, participantes, cidadãos.

\subsection{Considerações finais}

A preocupação diante da emergência e do progressivo aumento da violência nas escolas foi o que motivou a realização desta pesquisa. Embora a instituição escolar até tempos recentes tenha sido resguardada da incidência deste fenômeno, talvez por ser considerada uma espaço de educação e construção de saberes, indo de encontro a esta premissa básica, a violência tem surgido de forma significativa na instituição escolar.

Mas, desenvolver um trabalho sobre violência na escola não é das tarefas a mais fácil. Compreendê-la como processo, fruto da articulação entre homem, seu contexto e condições sociais, implica inseri-la em uma rede multidimensional, na qual diversos mecanismos agem juntos e simultaneamente em sua constituição. Assim, a violência na escola não pode ser estudada de modo dissociado do ambiente social onde os indivíduos, sujeitos da ação, estão inseridos. Como todos os fenômenos sociais, a violência também reafirma que o homem é a expressão de uma totalidade sócio-histórica.

As representações sociais que alunos de duas escolas públicas da rede estadual de ensino de Salvador/BA têm da violência na escola trazem consigo significados que a identificam, predominantemente, com agressão física e com a criminalidade. A violência verbal, expressa através de xingamentos, e a violência psicológica apresentada como discriminação, falta de respeito e desrespeito às diferenças, também são identificadas como formas de violência na escola. 
Segundo os estudantes, a violência na escola é causada por diversos fatores, que abrangem, mais especificamente, aqueles mais próximos deles. As questões macrossociais não foram abordadas por nenhum dos estudantes entrevistados. Uma vez que colocaram os alunos como responsáveis pela violência na escola, as causas levantadas estão relacionadas àquilo que os afeta diretamente, como a falta de atenção dos pais, a atitude do pessoal da escola para com eles, os amigos, as características da adolescência. As questões sociais estariam limitadas a segundo plano.

Ainda por apresentarem os próprios alunos como responsáveis pela violência na escola, a violência produzida pela própria escola, pelas pessoas que compõem este ambiente não foi mencionada em quase nenhum momento das entrevistas. E assim surge a pergunta: por que se consideram responsáveis? O fato de estarem submetidos ao sistema escolar, organizado de forma a conferir autoridade ao professor e ao aluno um papel passivo, poderia estar determinando uma representação segundo a qual, por ter autoridade, a equipe escolar (professores, funcionários) está legitimada para agir de forma "violenta", sem ser"acusada" por isso? Dessa forma, os estudantes parecem estar assumindo uma culpa que não sabem a quem atribuir, senão a eles mesmos.

Os significados que compõem a representação social dos estudantes sobre a violência e a violência na escola também podem fomentar a violência no contexto escolar. Afinal, há uma compreensão implícita nas entrevistas de que a escola é formadora, tem papel de educar, ensinar, o que pode estar insentando esta instituição da responsabilidade por promover uma violência que emerge da sua própria forma de organização; isentando a escola da obrigação de rever seus conceitos, princípios e métodos.

Seria necessário, portanto, que a escola fizesse uma reflexão acerca de seu papel, de sua função, pois a instituição escolar precisa ser concebida como um espaço de explosão de conflitos sociais (SANTOS, 2001), articuladora de relações que lhe são próprias e peculiares.

E surge mais uma pergunta: as representações que se têm da violência e da escola estariam impedindo que as iniciativas de ações preventivas alcançassem o ponto chave da questão da violência na escola, de fato prevenindo seu aparecimento?

Segundo Sposito (1998, p. 62), "a indagação incide sobre a possível criação de espaços públicos na vida escolar que permitiriam o reconhecimento das diferenças, a emergência de conflitos e de práticas de negociação para a sua resolução, a atenuação das desigualdades e a tolerância". Esta discussão indica a necessidade de pensar a prevenção da violência na escola de forma contextualizada, associando, às formas de prevenção sugeridas pelos 
estudantes, a responsabilidade que eles assumem pela violência na escola, o papel da escola e também da família.

Segundo a pesquisa, é importante apreender a forma de compreensão da violência na escola por parte dos estudantes, a fim de que as medidas de prevenção elaboradas sejam coerentes com a representação social que os estudantes fazem desse fenômeno.

As representações sociais sobre determinado fenômeno social são uma tentativa de interpretação e, simultaneamente, de construção de uma realidade social, pois elas funcionam na elaboração de comportamentos e na definição de posicionamento diante do fenômeno representado. Dessa forma, apreender a maneira como os estudantes entendem e significam a violência na escola significa alcançar como e por que se processa a violência no âmbito escolar e como ela se manifesta no cotidiano desses alunos.

Pelas questões levantadas neste trabalho fica clara a necessidade de pesquisas mais aprofundadas sobre o tema, que não dispensem a participação direta de estudantes no decorrer dos estudos. Como são eles os atores principais das relações mantidas nas escolas, incorporam nas suas interpretações do mundo e dos fenômenos sociais aquilo que acreditam ser o seu papel no contexto escolar.

\section{SOCIAL REPRESENTATIONS OF ELEMENTARY PUBLIC SCHOOL STUDENTS ON VIOLENCE IN THE SCHOOL}

ABSTRACT: This research sets out to describe the social representation made by elementary school students from two State schools in Salvador (Bahia) on school violence, by identifying the meanings associated with this violence, its roots and possible prevention. Data was collected through semi-structured interviews about violence in general, its interfaces with the school, possible causes and prevention etc. The data collected leads one to understand that violence is linked to physical abuse and crime, where the students themselves are responsible in the first place for the production of violence. Representations of violence in schools reveal meanings, such as disrespect and discrimination, as well as school violence in the form of physical, verbal and psychological aggression.

KEYWORDS: Violence. Violence in school. Social representations. Students.

\section{REFERÊNCIAS}

AQUINO, J. G. A violência escolar e a crise da autoridade docente. Caderno Cedes, v. 47, p. 7-19, 1998.

CAMACHO, L. M. Y. As sutilezas das faces da violência nas práticas escolares de adolescentes. Educação e Pesquisa, São Paulo, v. 27, n. 1, p. 123-140, 2001. 
DAVID, E. Violência e escola. Vertentes, v. 3, p. 23-32, Unesp, 1997.

DEBARBIEUX, E. A violência na escola francesa: 30 anos de construção social do objeto. Educação e Pesquisa, v. 27, n. 1, p. 163-193, 2001.

ITANI, A. A violência no imaginário dos agentes educativos. Caderno Cedes, v. 19, n. 47, p. 36-50, 1998.

JOVCHELOVITCH, S. Vivendo a vida com os outros: intersubjetividade, espaço público e representações sociais. In: GUARESCHI, P.; JOVCHELOVITCH, S. (Orgs.). Textos em representações sociais. 8. ed. Petrópolis: Vozes, 2003.

MINAYO, M. C. S.; SANCHES, O. Quantitativo-qualitativo: oposição ou complementaridade? Cadernos de Saúde Pública, v. 9, n. 3, p. 239-262, Rio de Janeiro, 1993.

RISTUM, M. Violência: uma forma de expressão da escola? Aprender - Caderno de Filosofia e Psicologia da Educação, v. 2, 2004.

RISTUM, M. O conceito de violência de professora do ensino fundamental. Tese (Doutorado em Educação) - Faculdade de Educação, Universidade Federal da Bahia, Salvador, 2001.

SÁ, C. P. Representações sociais: o conceito e o estado atual da teoria. In: SPINK, M. J. (Org.). O conhecimento no cotidiano. São Paulo: Brasiliense, 1993.

SANTOS, J. V. T. A violência na escola: conflitualidade social e ações civilizatórias. Educação e Pesquisa, v. 27, n. 1, p. 105-122, São Paulo, 2001.

SERAPIONI, M. Métodos qualitativos e quantitativos na pesquisa social em saúde: algumas estratégias para a integração. Ciência e Saúde Coletiva, v. 5, n. 1, p. 187-197, 2000.

SPINK, M. J. O conceito de representação social na abordagem psicossocial. Cadernos de Saúde Pública, v. 9, n. 3, p. 300-308, 1993.

SPINK, M. J. Desvendando as teorias implícitas: uma metodologia de análise das representações sociais. In: GUARESCHI, P.; JOVCHELOVITCH, S. (Orgs.). Textos em representações sociais. 8. ed. Petrópolis: Vozes, 2003.

SPOSITO, M. P. A instituição escolar e a violência. Cadernos de Pesquisa, v. 104, p. 5875, 1998.

SPOSITO, M. P. Um breve balanço da pesquisa sobre a violência escolar no Brasil. Educação e Pesquisa, v. 27, n. 1, p. 87-103, São Paulo, 2001.

Ana Flavia Souza Santana: Mestre em Psicologia pela Universidade Federal da Bahia (UFBA). Professora substituta da Universidade Estadual de Feira de Santana (UEFS), no Departamento de Educação.

E-mail : aflavia_santana@yahoo.com.br 